\title{
Social achievement goals, needs satisfaction, and coping among adolescents
}

\author{
Aikaterini Michou ${ }^{\mathrm{a}, *}$, Athanasios Mouratidis $^{\mathrm{b}}$, Evren Ersoy ${ }^{\mathrm{c}}$, Hasan Uğur ${ }^{\mathrm{d}}$ \\ a Bilkent University, Graduate School of Education, 06800 Bilkent, Ankara, Turkey \\ ${ }^{\mathrm{b}}$ Hacettepe University, Department of Psychology, 06800, Beytepe Campus, Ankara, Turkey \\ c Ylldz Technical University, Department of Guidance and Counseling, C-309, Davutpaşa, Esenler, İstanbul, Turkey \\ d Fatih University, Department of Education, Büyükçekmece, 34500 Istanbul, Turkey
}

\section{A R T I C L E I N F O}

\section{Article history:}

Received 10 February 2016

Received in revised form 8 May 2016

Accepted 12 May 2016

Available online 20 May 2016

\section{Keywords:}

Social achievement goals

Self-determination

Coping

Adolescents

Need satisfaction

\begin{abstract}
A B S T R A C T
In a sample of Turkish adolescents $(N=1614)$, we investigated whether pursuing social demonstration-approach goals (to attain popularity), next to social development goals (to cultivate meaningful relationships), explains differences in need satisfaction and frustration and coping. Cluster analysis showed that students who favored social development over social demonstration-approach goals reported less need frustration and defensive coping than students who favored both goals. These results were replicated with a prospective analysis with part of the initial sample $(N=425)$ as students who endorsed both goals reported more defensive coping five months later than students who mainly favored social development goals over social demonstration-approach goals.
\end{abstract}

(c) 2016 Elsevier Ltd. All rights reserved.

\section{Introduction}

Social achievement goals pertain to people's different strivings to attain success in the social domain (Ryan, Kiefer, \& Hopkins, 2004). Social development goals (i.e., cultivating meaningful relationships) are considered the most adaptive type of social achievement goals as they have been associated with more adaptive outcomes than social demonstration-approach goals (i.e., gaining popularity and social prominence) (Ryan \& Shim, 2006). It remains unclear however, whether concurrently pursuing both social development goals and social demonstrationapproach goals relates to better adjustment or whether social demonstration-approach goals interfere and degenerate the positive qualities of social development goals.

This is an interesting research question with theoretical and practical implications. From the theoretical standpoint, it is still debated whether the concurrent pursuit of different achievement goals can yield multiplicative or additive effects (Barron \& Harackiewicz, 2001). From the practical standpoint, it is important to clarify whether the endorsement of social demonstration-approach goals next to social developments goals should be encouraged as nowadays youngsters tend to value popularity and self-image relatively higher compared to previous

\footnotetext{
* Corresponding author at: Bilkent University, 06800 Bilkent, Ankara, Turkey.

E-mail addresses: aliki.michou@bilkent.edu.tr (A. Michou), athanasios@hacettepe.edu.tr (A. Mouratidis),ersoyevren2005@hotmail.com (E. Ersoy), hugur@fatih.edu.tr (H. Uğur).
}

generations (Twenge, Campbell, \& Freeman, 2012). We designed this study to address this particular research question - whether pursuing social development goals along with social demonstration-approach goals is as much need satisfying and effective in coping in demanding situations (Lazarus \& Folkman, 1984) as favoring the social development goals over the social demonstration-approach goals. We focused on coping as we consider it a significant marker of human functioning (Lazarus, 2006).

\subsection{Social achievement goals and the multiple goal perspective}

Following the academic achievement goal perspective, Ryan and associates introduced three types of social achievement goals that refer to striving for competence in the social domain (Ryan \& Shim, 2006; Ryan et al., 2004). Social development goals, correspond to mastery-approach academic goals (i.e., goals aiming at learning and developing competence in the academic domain) and reflect people's focus on developing social competence by cultivating the quality of relationships. Social demonstration-approach goals, correspond to performance-approach academic goals (i.e., goals aiming at demonstrating competence through outperforming others) and represent people's aim to demonstrate social competence by gaining popularity and others' admiration. Social demonstration-avoid goals, correspond to performance-avoidance academic goals (i.e., goals aiming at avoiding showing incompetence in the academic domain) and pertain to people's striving to avoid negative evaluation in social interactions. 
Presuming that social development goals reflect self-growth (Ryan \& Shim, 2006), researchers have found social development goals to relate negatively to loneliness (Liem, 2016; Shim, Cho, \& Wang, 2013) and positively to positive emotions (Shim, Wang, \& Cassady, 2013), prosocial behavior (Rudolph, Abaied, Flynn, Sugimura, \& Agoston, 2011), self-acceptance (Ryan \& Shim, 2006), peer relationships satisfaction (Liem, 2016), grades (Liem, 2016; Makara \& Madjar, 2015), and, relevant to the present study to adaptive coping in stressful situations with friends (Shin \& Ryan, 2012).

In contrast, social demonstration-approach goals have been associated negatively with personal growth (Ryan \& Shim, 2006) and prosocial behavior (Rodkin, Ryan, Jamison, \& Wilson, 2013) and positively with aggression (Shim \& Ryan, 2012) disruptive behavior (Shim, Cho, et al., 2013) and suboptimal coping strategies (Shin \& Ryan, 2012). Occasionally however, social demonstration-approach goals have been linked positively with joy (Shim, Wang, et al., 2013) and perceived popularity (Ryan \& Shim, 2008). Regarding social demonstration-avoid goals, they have been found to associate with negative outcomes such as low perceived acceptance, anxiety and internalizing behavior, and avoidance coping, and sometimes with some positive ones, such as less aggression (Ryan \& Shim, 2008) better grades (Makara \& Madjar, 2015) and more collective efficacy (Jones \& Ford, 2014).

Taken together, research has highlighted the adaptive character of social development goals over the social demonstration ones. In the academic domain, research has also highlighted the adaptive character of mastery-approach goals (i.e., the corresponding to the social development goals). However, in the academic domain a multiple goal perspective has been adopted for academic-related achievement goals, suggesting that endorsing both mastery-approach and performance-approach goals could yield benefits to students (Barron \& Harackiewicz, 2001). Based on this multiple goal perspective, we examined whether endorsing both social development goals and social demonstration-approach goals would be equally, if not more, adaptive than favoring social development goals over social demonstration-approach goals.

Research in the framework of Self-determination Theory (SDT; Deci \& Ryan, 2000) has shown that the intrinsic aspiration of establishing meaningful relationships (which is conceptually similar to social development goals) facilitates the satisfaction of the basic psychological needs for autonomy (one's desire to define her own actions, thoughts, and feelings), competence (a need to interact effectively with the environment), and relatedness (one's desire to be connected with, loved and cared about by important others) and therefore it is related to wellbeing (Kasser \& Ryan, 1996). In contrast, the extrinsic aspiration of attaining popularity (which conceptually overlaps with social demonstration-approach goals) thwarts the psychological needs and relates to depression and anxiety (Kasser \& Ryan, 1996).

Extrapolating from this line of work to social achievement goals, we presumed that social development and social demonstration-approach goals represent, respectively, an intrinsic and extrinsic type of aspirations and therefore favoring social development goals over social demonstration goals could explain more need satisfaction, less need frustration and better coping strategies (as different goals may entail different coping mechanisms Carver \& Connor-Smith, 2010; Weinstein \& Ryan, 2011) than endorsing both social development and social demonstration-approach goals.

\subsection{The present research}

We set two objectives in our research. First, given that people may concurrently pursue to different degree the three social achievement goals, we tested through a cluster analysis whether students who strongly endorse both social development and social demonstration-approach goals would differ in needs satisfaction and frustration and coping than students who favor mainly social development goals. Prior research has indicated that all the three social achievement goals are positively intercorrelated (Ryan \& Shim, 2008; Shim \& Ryan, 2012; Shin \& Ryan, 2012), as they can be concurrently endorsed (Shim \& Finch, 2014), though each one to different degree. More important, prior SDT-based research has also indicated that endorsing extrinsic aspirations (e.g., gain popularity; a social demonstration-approach goal) along with intrinsic ones (e.g., develop meaningful relationships; a social development goal) lead to suboptimal outcomes (Niemiec, Ryan, \& Deci, 2009). We relied on this set of findings to hypothesize that students who pursue both social development goals and social demonstration-approach goals would report less need satisfaction, higher need frustration, and less adaptive coping (Hypothesis 1) than students who favor social development goals over social demonstration-approach goals.

Second, we tested whether these differences in coping would emerge again five months later (T2). We hypothesized that students who favored social development goals over social demonstration goals would report better coping strategies few months later than students who equally espoused social development goals and social demonstration-approach goals (Hypothesis 2). Regarding social demonstrationavoid goals, we made no particular hypothesis because although prior research has shown its negative nature (Ryan \& Shim, 2006), research conducted with adolescents has shown that these type of social goals are not necessarily linked with negative outcomes (Ryan \& Shim, 2008; Shim, Cho, et al., 2013; Shim, Wang et al., 2013).

\section{Method}

\subsection{Participants}

Nine hundred seventy-five 6th grade (12-year old) and 639 9thgrade (15-year old) Turkish adolescent students from, respectively 12 middle and 6 high schools located in the metropolitan area of Istanbul, Turkey, participated at T1 (October of 2014); among them 425 (73.8\% 6 -the graders) participated also at T2, five months later. Data were collected during one-hour class-session. After getting consent from the Ministry of Education, the school principals and parents, a research assistant explained the purpose of the study and assured students that their participation would be anonymous and voluntary. An unexpected administrative problem (the page that contained questions on demographics was omitted), prevented us from getting information about the gender and the precise age of participants, but as school principals informed us in retrospect, the distribution of gender in the classes that we sampled was approximately equal. The questionnaires were translated and back-translated by two experts and adjusted according to the procedures proposed by Hambleton (1994). A 5-point Likert-type scale ( $1=$ strongly disagree; $5=$ strongly agree) was used in all the measures.

\subsection{Measures}

\subsubsection{Social achievement goals}

We used the Ryan and Shim's (2008) scale to assess students' social development ( 6 items; e.g., "I like it when I learn better ways to get along with friends"), social demonstration-approach (6 items; e.g., "It is important to me that other kids think I am popular."), and social demonstration-avoid goals ( 6 items; e.g., "I try not to do anything that might make other kids tease me."). A Confirmatory Factor Analysis (CFA) showed acceptable fit after two modifications. First, the social demonstration-approach item "I try to do things that make me look good to other kids" showed high cross-loading with the social development latent factor. In retrospect, we presumed that this item was equally perceived as an item implying endorsing social development goal and we therefore dropped it. Second, we let the errors of two items from the social demonstration-avoid goals to covary. The fit for the modified scale was as follows: Satorra-Bentler $\chi^{2}(115, N=1614)=463.94$, $p<0.01, \mathrm{CFI}=0.933$, SRMR $=0.051$, RMSEA $=0.046$ (90\% CI: 0.042- 
0.050). In light of these findings, we computed a composite score for each of the three subscales by averaging the items of each subscale.

\subsubsection{Basic needs satisfaction and frustration}

The Basic Psychological Needs Scale (Deci \& Ryan, 2000) was used to assess students' need satisfaction and frustration in their school life. Participants indicated the degree to which their psychological needs for autonomy ( 4 items; e.g., "I feel like I am free to decide for myself how to live my life"), competence ( 3 items; e.g., "I have been able to learn interesting new skills recently"), and relatedness ( 5 items; e.g., "People in my life care about me") were satisfied at school. Accordingly, we used the 3 reverse-worded items that corresponded to each of the three subscales to assess the degree to which their needs for autonomy (e.g., "I feel pressure in my life"), competence (e.g., "Often, I do not feel very competent"), and relatedness ("There are not many people that I am close to") were frustrated. A CFA with two latent factors, one for need satisfaction and another one for need frustration, yielded the following fit: Satorra-Bentler $\chi^{2}(188, N=1614)=653.79, p<0.01, \mathrm{CFI}=0.909$, $\mathrm{SRMR}=0.046, \mathrm{RMSEA}=0.042(90 \% \mathrm{CI}: 0.039-0.046)$. We computed a composite score for need satisfaction and need frustration by averaging the respective subscales.

\subsubsection{Coping}

The brief COPE inventory (Carver, 1997) was used to assess thirteen coping strategies ( 2 items per each strategy) in stressful events. A principal component analysis (with Promax rotation) with the thirteen twoitem average scores of coping components assessed at both $\mathrm{T} 1$ and $\mathrm{T} 2$ extracted three factors with eigenvalues higher than 1.0. However, because there were two cross-loadings and because the third factor yielded an eigenvalue marginally higher than the cut-off criterion of 1.0 (i.e., eigenvalue 1.06; explained variance $8.17 \%$ ), we decided to rerun the same analyses by setting a priori a two-factor solution. In light of the obtained factor solution, we termed the first factor as adaptive coping and the second one as defensive coping. Yet, content-wise we considered that self-distraction conceptually differs from the other forms of coping and we therefore dropped this particular subscale from the adaptive coping score. ${ }^{1}$ Therefore, we created an average score of adaptive coping by aggregating the items tapping active coping, planning, positive framing, acceptance, religious, emotional support, and instrumental and we did the same for the defensive coping by aggregating the items assessing humor, denial, venting emotions, selfblame, and behavioral disengagement.

\section{Results}

3.1. Differences in the concurrent pursuit of the three social achievement goals

Descriptive statistics, bivariate correlations, and Cronbach alphas of the measured variables are presented in Table 1 . We conducted a cluster analysis - a technique that classifies people who share common characteristics (i.e., social achievement goals, in our case) into the same group (Borgen \& Barnett, 1987) - to investigate students' different profiles regarding their social achievement goals. Cluster analysis is sometimes called person-centered analysis because it tries to uncover how the variables combine across individuals. After dropping 98 outliers (6.1\% of the sample), according to the criteria proposed by Cohen, Cohen, West, and Aiken (2003) we followed Hair and Black's (2004) recommendations, and first ran a hierarchical cluster analysis (with Ward's method estimate) to determine the number of clusters that emerged. Inspection of the BIC index suggested a three-cluster solution. Using the centroids of the three-cluster solution, we then performed a $k$ means clustering.

\footnotetext{
${ }^{1}$ Had we kept the self-distraction subscale in the active coping factor, the core findings from all the subsequent analyses would have remained the same.
}

Table 2 shows the means of the three dimensions comprising each cluster (upper panel) while their $z$-scores are graphically depicted in Fig. 1. The derived solution was tested for its stability by splitting the sample into two halves and performing $k$-means clustering in each half by using as initial centers the ones that were derived by the hierarchical clustering in the other half. The solution of each half was then cross-tabulated with the respective solution that was derived from the full sample. The results showed acceptable consistency (kappa's agreement $>0.95$ for both halves).

After inspecting the means of the observed scores and the respective $z$-scores, we labelled the three groups as relatively low social, relatively low popularity, and relatively high social group. We conducted a Multivariate Analysis of Variance (MANOVA) to examine whether the three groups differed in the mean scores of three social achievement goals. The MANOVA with the three social achievement goals being the dependent variables and cluster membership being the predictor was, as expected, statistically significant, Wilk's $\Lambda=0.153, F(6,3022)=788.28$, $p<0.01$, multivariate $\eta^{2}=0.61$. We then performed follow-up ANOVAs to examine in which three goals there were statistically significant differences among the three groups followed by post-hoc tests for each of the dependent variables to test which group differed to each other. Bonferroni correction was employed to control for inflated type I error (due to multiple comparisons). These tests showed statistically significant differences among the three groups in all the three social achievement goals (Table 2), providing support to the distinction of the three clusters.

\subsection{Differences in need satisfaction, need frustration and coping (Hypothe- sis 1)}

To test to what extent the different profiles differed in need satisfaction or frustration and coping, we conducted a second MANOVA with cluster membership being the independent variable and need satisfaction, need frustration, adaptive coping, and defensive coping being the dependent variables. The three groups significantly differed Wilk's $\Lambda=0.875, F(8,3008)=26.00, p<0.01$, multivariate $\eta^{2}=0.07$.

Follow-up ANOVA and post-hoc test, adjusted for inflated type I error risk, revealed that the students in the relatively low social group reported lower need satisfaction than the other two groups in which students did not differ from each other (Table 2 lower panel). Also, in partial support of Hypothesis 1, students in the relatively low popularity group reported significantly less need frustration than the relatively high social group, while the relatively low social group did not differ from the two groups either. A similar pattern existed for coping as students in the relatively low social group reported less adaptive coping than the other two groups. Yet, the latter two groups differed in the defensive coping as students with a relatively low popularity profile reported less defensive coping than students with the relatively high social goal profile. The relatively low popularity and low social goal groups did not differ from each other. Taken together, the group comparisons provided partial support to Hypothesis 1 as the relatively low popularity group did differ from the relatively high social group in need frustration and defensive coping (but not in need satisfaction).

\subsection{Differences in coping five months later (Hypothesis 2)}

We examined through MANOVA) to what extent cluster membership could explain differences in T2 adaptive and defensive coping. The MANOVA was statistically significant, Wilk's $\Lambda=0.919, F(4$, $790)=8.55, p<0.01$, multivariate $\eta^{2}=0.04$. Follow-up ANOVA showed, after post-hoc adjustment for inflated type I error, statistically significant differences among the three groups in both T2 adaptive and defensive coping. Specifically, students in the relatively low social group reported less adaptive coping in T2 than the other two groups which did not differ from each other (Table 2, lower panel). Furthermore, students in the relatively low social group and the relatively low popularity 
Table 1

Cronbach alphas (on the diagonal), means, standard deviations, and bivariate correlations among the measured variables of the study.

\begin{tabular}{|c|c|c|c|c|c|c|c|c|c|c|c|c|}
\hline Variables & 1 & 2 & 3 & 4 & 5 & 6 & 7 & 8 & 9 & $N$ & $M$ & $S D$ \\
\hline \multicolumn{13}{|l|}{ Time $1(\mathrm{~T} 1) N=1614$} \\
\hline 1. Social development goals & .72 & & & & & & & & & & 4.09 & 0.64 \\
\hline 2. Social demo-approach goals & .21 & .77 & & & & & & & & & 2.70 & 0.95 \\
\hline 3. Social demo-avoidance goals & .46 & .23 & .76 & & & & & & & & 4.06 & 0.82 \\
\hline 4. Need satisfaction & .39 & .07 & .24 & .81 & & & & & & & 3.94 & 0.59 \\
\hline 5. Need frustration & -.05 & .12 & .05 & -.29 & .78 & & & & & & 2.71 & 0.76 \\
\hline 6. Adaptive coping (T1) & .40 & .05 & .25 & .54 & -.07 & .81 & & & & & 3.06 & 0.49 \\
\hline 7. Defensive coping (T1) & .06 & .22 & .06 & .01 & .42 & .24 & .68 & & & & 2.40 & 0.53 \\
\hline \multicolumn{13}{|l|}{ Time $2(\mathrm{~T} 2) N=425$} \\
\hline 8. Adaptive coping (T2) & .25 & .11 & .14 & .32 & -.06 & .30 & .00 & .85 & & & 2.98 & 0.54 \\
\hline 9. Defensive coping (T2) & .12 & .25 & .09 & .10 & .19 & .02 & .33 & .33 & .72 & & 2.58 & 0.57 \\
\hline
\end{tabular}

Note. Correlations equal or greater than $|.05|$ and $|.07|$ for T1 and greater than $|.10|$ and $|.14|$ for T2 are statistically significant at the alpha level of .05 and .01 , respectively.

group reported less defensive coping in T2 than students in the relatively high social group.

\section{Discussion}

We employed a person-centered approach to examine whether favoring social development goals over social demonstration-approach goals as compared to the concurrent pursuit of both social development goals and social demonstration-approach goals explain differences in need satisfaction, need frustration, and coping.

Comparisons among the three profiles showed that adopting both social development and social demonstration-approach goals is less adaptive than disregarding social demonstration-approach goals and focusing more on social development goals. This is because students in the latter group reported less need frustration and defensive coping than students who strongly endorsed both social development and social demonstration-approach goals. Specifically, although students in both groups did not differ in need satisfaction and adaptive coping, students in the relatively high social group appeared to suffer more as they admitted more need frustration and defensive coping. Furthermore, these differences in defensive coping emerged again few months later. Taken together these results imply that aiming at developing social competence through developing meaningful relationships and at the same time aiming at demonstrating social competence by becoming popular, may diminishes one's optimal functioning.

These findings are in accord with previous studies that have shown social demonstration-approach goals to relate to both negative (e.g., aggression Shim \& Ryan, 2012, social aggression Dawes \& Xie, 2014 and disruptive behavior Shim, Cho, et al., 2013) and positive social outcomes (e.g., joy Shim, Wang, et al., 2013, perceived popularity Ryan \& Shim, 2008 and actual popularity Dawes \& Xie, 2014). However, our study builds on previous ones as we found that the pursuit of social demonstration-approach goals may cancel out some of the positive implications that the pursuit of social development goals might have in students' need frustration and defensive coping.

Our findings are also in accord with previous ones showing the negative implications of endorsing both intrinsic and extrinsic goals on well-being (Kasser \& Ryan, 2001) and suggest that the content of the endorsed goal is important for one's psychological development. Probably, this is because the goal content is associated with different degree of need satisfaction and frustration. Seeking to be popular could imply a sense of high social competence (i.e., satisfaction of need for competence), connectedness (i.e., satisfaction of need for relatedness), and agency (i.e., satisfaction of need for autonomy). However, it could also imply a sense of insecurity that urges the person to become popular to prove his or her personal value. Hence, it could also imply a sense of loneliness and alienation of one's profound self in social relationships as the person turns to others for approval. This means that the pursuit of social demonstration-approach goals next to social development goals could become a double-edge sword as it could entail both need satisfaction and need frustration and consequently a use of both adaptive and defensive coping. It seems that "less" is sometimes more (Vansteenkiste et al., 2004) as favoring social development goals over social demonstration-approach goals relates to more optimal outcomes.

However further research could clarify whether the pursuit of both social demonstration-approach and social development goals lead to

Table 2

Mean group differences in the constituting dimensions and the measured correlates of T1 (middle panel) and T2 (lower panel) as a function of social achievement goal profiles.

\begin{tabular}{|c|c|c|c|c|c|c|c|c|c|c|c|}
\hline \multirow[b]{4}{*}{ Variables } & \multicolumn{9}{|l|}{ Clusters } & \multirow[b]{4}{*}{$F(2,1513)$} & \multirow[b]{4}{*}{$\eta^{2}$} \\
\hline & \multirow{2}{*}{\multicolumn{3}{|c|}{$\begin{array}{l}\text { Low social goal } \\
n=424(28.0 \%) \\
\end{array}$}} & \multirow{2}{*}{\multicolumn{3}{|c|}{$\begin{array}{l}\text { Non-popularity goal } \\
n=558(36.8 \%)\end{array}$}} & \multirow{2}{*}{\multicolumn{3}{|c|}{$\begin{array}{l}\text { High social goal } \\
n=534(35.2 \%) \\
\end{array}$}} & & \\
\hline & & & & & & & & & & & \\
\hline & & $M$ & $S D$ & $z$-Score & $M$ & $S D$ & $z$-Score & $M$ & $S D$ & & \\
\hline \multicolumn{12}{|c|}{ Constituting dimensions ( $N=1516$ cases $)$} \\
\hline S. development goals & -0.94 & $3.48^{\mathrm{a}}$ & $(0.45)$ & 0.30 & $4.28^{\mathrm{b}}$ & $(0.41)$ & 0.60 & $4.47^{\mathrm{c}}$ & $(0.40)$ & $717.55^{* *}$ & .49 \\
\hline S. demo-approach goals & -0.32 & $2.40^{\mathrm{a}}$ & $(0.68)$ & -0.65 & $2.09^{\mathrm{b}}$ & $(0.50)$ & 0.98 & $3.63^{c}$ & $(0.51)$ & $917.72^{* *}$ & .57 \\
\hline S. demo-avoid goals & -1.00 & $3.24^{\mathrm{a}}$ & $(0.55)$ & 0.36 & $4.36^{\mathrm{b}}$ & $(0.50)$ & 0.63 & $4.58^{\mathrm{c}}$ & $(0.45)$ & $955.26^{* *}$ & .56 \\
\hline \multicolumn{10}{|l|}{ Time 1 correlates ( $N=1511$ cases $)$} & \multicolumn{2}{|l|}{$F(2,1507)$} \\
\hline Need satisfaction & & $3.69^{\mathrm{a}}$ & $(0.58)$ & & $3.99^{\mathrm{b}}$ & $(0.54)$ & & $4.08^{\mathrm{b}}$ & $(0.58)$ & $60.69 * *$ & .08 \\
\hline Need frustration & & $2.68^{\mathrm{ab}}$ & $(0.66)$ & & $2.65^{\mathrm{a}}$ & $(0.74)$ & & $2.79^{\mathrm{b}}$ & $(0.82)$ & $5.26^{* *}$ & .01 \\
\hline $\mathrm{T} 1$ adaptive coping & & $2.86^{\mathrm{a}}$ & $(0.43)$ & & $3.10^{\mathrm{b}}$ & $(0.46)$ & & $3.17^{\mathrm{b}}$ & $(0.48)$ & $57.70^{* *}$ & .07 \\
\hline $\mathrm{T} 1$ defensive coping & & $2.35^{\mathrm{a}}$ & $(0.48)$ & & $2.33^{\mathrm{a}}$ & $(0.50)$ & & $2.50^{\mathrm{b}}$ & $(0.54)$ & $16.56^{* *}$ & .02 \\
\hline \multirow[t]{2}{*}{ Time 2 correlates ( $N=399$ cases $)$} & \multicolumn{3}{|c|}{$n=117(29.4 \%)$} & \multicolumn{3}{|c|}{$n=145(36.4 \%)$} & \multicolumn{3}{|c|}{$n=137(34.2 \%)$} & \multicolumn{2}{|l|}{$F(2,393)$} \\
\hline & & $M$ & $S D$ & & $M$ & $S D$ & & $M$ & $S D$ & & \\
\hline $\mathrm{T} 2$ adaptive coping & & $2.84^{\mathrm{a}}$ & $(0.50)$ & & $2.97^{\mathrm{ab}}$ & $(0.54)$ & & $3.11^{b}$ & $(0.55)$ & $84.50^{* *}$ & .04 \\
\hline $\mathrm{T} 2$ defensive coping & & $2.45^{\mathrm{a}}$ & $(0.53)$ & & $2.50^{\mathrm{a}}$ & $(0.45)$ & & $2.78^{b}$ & $(0.85)$ & $13.14^{* *}$ & .06 \\
\hline
\end{tabular}

Note. Correlates cluster means not sharing the same superscripts across the same row significantly differ at the $\alpha=0.008$ level. 


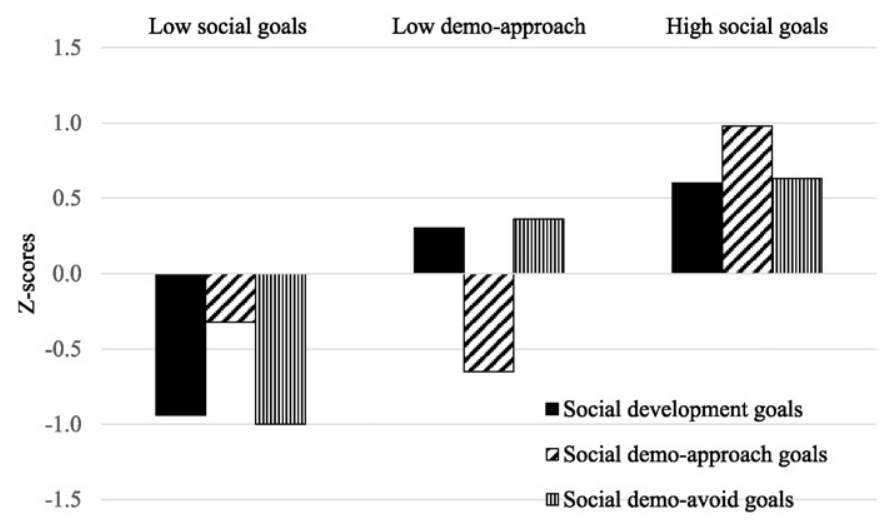

Fig. 1. Mean z-scores of social achievement goals for the three-cluster solution.

adaptive outcomes when both goals are attained, although SDT-based research has indicated that successful pursuit of extrinsic aspirations (among which popularity is included) barely do predict positive outcomes (Niemiec et al., 2009; Van Hiel \& Vansteenkiste, 2009). Future research may also need to examine under which specific circumstances the concurrent pursuit of both social achievement goals could lead only to positive outcomes. Again, research conducted under the framework of SDT has shown that extrinsic aspirations are unrelated to positive outcomes even when the social context promotes such goals (e.g., Kasser \& Ahuvia, 2002). Yet, it remains sketchy what are the implications when both social development goals and social demonstration goals attained and (or) when the social environment promotes both goals.

Our research also showed that the relatively low social group was non-optimal, as students with that profile reported less need satisfaction and adaptive coping than the other students. However, students in this group reported also less defensive coping compared to their counterparts in the relatively high social group, suggesting that such students are more in a "neutral" or "withdrawn" position.

About social demonstration-avoid goals, two findings are noteworthy. First, similar to a recent study with adolescents (Shim \& Finch, 2014), they were positively, and quite moderately, related to social development goals; second, they appeared not to cancel out, in the same way social demonstration-approach goals did, the positive associations of social development goals to need satisfaction and adaptive coping. These findings perhaps tell something about the role of social demonstration-avoid goals as they seem less detrimental than social demonstration-approach goals. Moreover, taking into consideration that social demonstration-avoid goals associated positively with need satisfaction and adaptive coping and almost marginally positively with need frustration and defensive coping, we assume that, unlike their counterparts in the academic domain (i.e., the performance-avoidance goals), the social demonstration-avoid goals could be less maladaptive than social demonstration-approach goals. In support of this claim, Liem (2016) has recently found in a sample of adolescent students, social demonstration-avoid goals not to associate positively with negative outcomes or positively with negative ones. However, further research is needed to delineate the relation of social demonstration-avoid goals to optimal functioning as several previous studies have found social demonstration-avoid goals to relate positively to anxiety and internalizing behavior (Ryan \& Shim, 2008).

In sum, this study highlights the adaptive nature of social development goals over the social demonstration ones, a conclusion which replicates prior research (e.g., Ryan \& Shim, 2006) and which mirrors the respective findings concerning the research conducted in the academic domain where, again, mastery-approach goals more reliably predict positive achievement outcomes (Hulleman \& Senko, 2010). Also, it shows that although social demonstration-approach goals entail an approach orientation, they seem less adaptive compared to social demonstration-avoid goals and their counterparts in the academic domain, the performance-approach goals (Senko, Hulleman, \& Harackiewicz, 2011). And, although social demonstration-avoid goals orient the person away from an undesired situation, they seem less harmful compared to the respective academic-related performanceavoidance goals.

\section{Limitations}

Given our research design, no causality can be inferred as social achievement goals, needs, and coping may be reciprocally influenced by each other and by other factors such as the context (e.g., peer relationships). Moreover, we were unable to analyze whether our findings are gender invariant as we missed this information. Also, the observed associations were based on adolescents' self-reports, whereas generalizations to other cultures and ages should be made with caution. For instance, our principal component analysis showed that religious coping was classified as an adaptive coping style but it remains unclear whether this is the case among adolescents from western cultures (see Krageloh, 2011).

\section{Conclusion}

Social achievement goals can explain adolescents' differences in need satisfaction and coping. Aiming towards cultivating one's social relationships seems to align more with one's inner psychological needs and to predict more effective coping than aiming at gaining popularity and high social status. Teachers and parents need to know that emphasizing popularity goals next to social development goals may impede adolescents' optimal functioning.

\section{References}

Barron, K. E., \& Harackiewicz, J. M. (2001). Achievement goals and optimal motivation: Testing multiple goal models. Journal of Personality and Social Psychology, 80, 706-722. http://dx.doi.org/10.1037//0022-3514.80.5.706.

Borgen, F. H., \& Barnett, D. C. (1987). Applying cluster analysis in counseling psychology research. Journal of Counseling Psychology, 34, 456-468. http://dx.doi.org/10.1037/ 0022-0167.34.4.456.

Carver, C. S. (1997). You want to measure coping but your protocol's too long: Consider the Brief COPE. International Journal of Behavioral Medicine, 4, 92-100.

Carver, C. S., \& Connor-Smith, J. (2010). Personality and coping. Annual Review of Psychology, 61, 679-704. http://dx.doi.org/10.1146/annurev.psych.093008.100352.

Cohen, J., Cohen, P., West, S. G., \& Aiken, L. S. (2003). Applied multiple regression analysis for the behavioral sciences (3rd ed.). Mahwah, NJ: Lawrence Erlbaum.

Dawes, M., \& Xie, H. (2014). The role of popularity goal in early adolescents' behaviors and popularity status. Developmental Psychology, 50, 489-497. http://dx.doi.org/10. 1037/a0032999.

Deci, E. L., \& Ryan, R. M. (2000). The "what" and "why" of goal pursuits: Human needs and the self-determination of behavior. Psychological Inquiry, 11, 227-268. http://dx.doi. org/10.1207/s15327965pli1104_01.

Hair, J. F., \& Black, W. C. (2004). Cluster analysis. In L. G. Grimm, \& P. R. Yarnold (Eds.), Reading and understanding more multivariate statistics (pp. 147-205). Washington DC: American Psychological Association.

Hambleton, R. K. (1994). Guidelines for adapting educational and psychological tests: A progress report. European Journal of Psychological Assessment, 10, 229-240.

Hulleman, C. S., \& Senko, C. (2010). Up around the bend: Forecasts for achievement goal theory and research in 2020. Advances in Motivation and Achievement, 16, 71-104.

Jones, M. H., \& Ford, J. M. (2014). Social achievement goals, efficacious beliefs, and math performance in a predominately African American high school. Journal of Black Psychology, 40, 239-262. http://dx.doi.org/10.1177/0095798413483556.

Kasser, T., \& Ahuvia, A. (2002). Materialistic values and well-being in business students. European Journal of Social Psychology, 32, 137-146. http://dx.doi.org/10.1002/Ejsp.85.

Kasser, T., \& Ryan, R. M. (1996). Further examining the American dream: Differential correlates of intrinsic and extrinsic goals. Personality and Social Psychology Bulletin, 22, 280-287. http://dx.doi.org/10.1177/0146167296223006.

Kasser, T., \& Ryan, R. M. (2001). Be careful what you wish for: Optimal functioning and the relative attainment of intrinsic and extrinsic goals. In P. Schmuck, \& K. M Sheldon (Eds.), Life goals and well-being: Towards a positive psychology of human striving (pp. 116-131). Gottingen, the Netherlands: Hogerfe \& Huber.

Krageloh, C. U. (2011). A systematic review of studies using the brief COPE: Religious coping in factor analyses. Religions, 2, 216-246. http://dx.doi.org/10.3390/rel2030216.

Lazarus, R. S. (2006). Emotions and interpersonal relationships: Toward a person-centered conceptualization of emotions and coping. Journal of Personality, 74, 9-46. http://dx.doi.org/10.1111/j.1467-6494.2005.00368.

Lazarus, R. S., \& Folkman, S. (1984). Stress, appraials, and coping. New York: Springer. 
Liem, G. A. D. (2016). Academic and social achievement goals: Their additive, interactive, and specialized effects on school functioning. British Journal of Educational Psychology, 86, 37-56. http://dx.doi.org/10.1111/bjep.12085.

Makara, K. A., \& Madjar, N. (2015). The role of goal structures and peer climate in trajectories of social achievement goals during high school. Developmental Psychology, 51, 473-488. http://dx.doi.org/10.1037/a0038801.

Niemiec, C. P., Ryan, R. M., \& Deci, E. L. (2009). The path taken: Consequences of attaining intrinsic and extrinsic aspirations in post-college life. Journal of Research in Personality, 43, 291-306. http://dx.doi.org/10.1016/j.jrp.2008.09.001.

Rodkin, P. C., Ryan, A. M., Jamison, R., \& Wilson, T. (2013). Social goals, social behavior, and social status in middle childhood. Developmental Psychology, 49, 1139-1150. http:// dx.doi.org/10.1037/a0029389.

Rudolph, K. D., Abaied, J. L., Flynn, M., Sugimura, N., \& Agoston, A. M. (2011). Developing relationships, being cool, and not looking like a loser: Social goal orientation predicts children's responses to peer aggression. Child Development, 82, 1518-1530. http://dx. doi.org/10.1111/j.1467-8624.2011.01631.x.

Ryan, A. M., \& Shim, S. S. (2006). Social achievement goals: The nature and consequences of different orientations toward social competence. Personality and Social Psychology Bulletin, 32, 1246-1263. http://dx.doi.org/10.1177/0146167206289345.

Ryan, A. M., \& Shim, S. S. (2008). An exploration of young adolescents' social achievement goals and social adjustment in middle school. Journal of Educational Psychology, 100, 672-687. http://dx.doi.org/10.1037/0022-0663.100.3.672.

Ryan, A. M., Kiefer, A. K., \& Hopkins, N. B. (2004). Young adolescents' social motivation: An achievement goal perspective. In P. R. Pintrich, \& M. L. Maehr (Eds.), Advances in motivation and achievement, vol. 13. (pp. 301-330). Greenwich, CT: Jai Press.

Senko, C., Hulleman, C. S., \& Harackiewicz, J. M. (2011). Achievement goal theory at the crossroads: Old controversies, current challenges, and new directions. Educational Psychologist, 46, 26-47. http://dx.doi.org/10.1080/00461520.2011.538646.

Shim, S. S., \& Finch, W. H. (2014). Academic and social achievement goals and early adolescents' adjustment: A latent class approach. Learning and Individual Differences, 30 98-105. http://dx.doi.org/10.1016/j.lindif.2013.10.015.
Shim, S. S., \& Ryan, A. M. (2012). What do students want socially when they arrive at college? Implications of social achievement goals for social behaviors and adjustment during the first semester of college. Motivation and Emotion, 36, 504-515. http://dx. doi.org/10.1007/s11031-011-9272-3.

Shim, S. S., Cho, Y., \& Wang, C. (2013a). Classroom goal structures, social achievement goals, and adjustment in middle school. Learning and Instruction, 23, 69-77. http:// dx.doi.org/10.1016/j.learninstruc.2012.05.008.

Shim, S. S. Wang C. \& Cassady, J. C. (2013b). Emotional well-being: The role of social achievement goals and self-esteem. Personality and Individual Differences, 55, 840-845. http://dx.doi.org/10.1016/j.paid.2013.07.004.

Shin, H. Y., \& Ryan, A. M. (2012). How do young adolescents cope with social problems? An examination of social goals, coping with friends, and social adjustment. Journal of Early Adolescence, 32, 851-875. http://dx.doi.org/10.1177/0272431611429944.

Twenge, J. M., Campbell, W. K., \& Freeman, E. C. (2012). Generational differences in young adults' life goals, concern for others, and civic orientation, 1966-2009. Journal of Personality and Social Psychology, 102, 1045-1062. http://dx.doi.org/10.1037/ a0027408.

Van Hiel, A., \& Vansteenkiste, M. (2009). Ambitions fulfilled? The effects of intrinsic and extrinsic goal attainment on older adults' ego-integrity and death attitudes. The International Journal of Aging and Human Development, 68, 27-51. http://dx.doi.org/ 10.2190/AG.68.1.b.

Vansteenkiste, M., Simons, J. Lens, W. Soenens, B., Matos, L, \& Lacante, M. (2004). Less is sometimes more: Goal content matters. Journal of Educational Psychology, 96, 755-764. http://dx.doi.org/10.1037/0022-0663.96.4.755.

Weinstein, N., \& Ryan, R. M. (2011). A self-determination theory approach to understanding stress incursion and responses. Stress and Health, 27, 4-17. http://dx.doi.org/10. 1002/smi.1368. 